\title{
Mechanisms of HIV Transcriptional Regulation and Their Contribution to Latency
}

\author{
Gillian M. Schiralli Lester and Andrew J. Henderson \\ Section of Infectious Diseases, Department of Medicine, Boston University School of Medicine, Boston, MA 02118, USA \\ Correspondence should be addressed to Andrew J. Henderson, andrew.henderson@bmc.org
}

Received 15 February 2012; Accepted 9 April 2012

Academic Editor: Suryaram Gummuluru

Copyright ( $\odot 2012$ G. M. Schiralli Lester and A. J. Henderson. This is an open access article distributed under the Creative Commons Attribution License, which permits unrestricted use, distribution, and reproduction in any medium, provided the original work is properly cited.

\begin{abstract}
Long-lived latent HIV-infected cells lead to the rebound of virus replication following antiretroviral treatment interruption and present a major barrier to eliminating HIV infection. These latent reservoirs, which include quiescent memory T cells and tissueresident macrophages, represent a subset of cells with decreased or inactive proviral transcription. HIV proviral transcription is regulated at multiple levels including transcription initiation, polymerase recruitment, transcription elongation, and chromatin organization. How these biochemical processes are coordinated and their potential role in repressing HIV transcription along with establishing and maintaining latency are reviewed.
\end{abstract}

\section{Introduction}

A critical step in the HIV life cycle is transcriptional regulation of the integrated provirus. Robust transcription assures that sufficient mRNA and genomic RNA are produced for efficient virus assembly and infectivity. Repression of HIV transcription leads to the establishment of HIV latency, which creates repositories for infectious and drug-resistant viruses that reemerge upon treatment failure or interruption [1-4]. The existence of long-lived stable HIV reservoirs was demonstrated by the rebound of virus replication following highly active antiretroviral therapy (HAART) interruption [5-8]. These latent reservoirs, which include quiescent memory T cells, tissue-resident macrophages $[9,10]$, and potentially hematopoietic stem cells [11], although this is still controversial [12], represent long-lived subsets of cells with decreased or inactive proviral transcription. In general, studies with chronically and acutely infected cells show that mutations in Tat $[13,14]$, absence of cellular transcription factors [15-18], miRNA machinery $[19,20]$, and proviral integration into transcriptionally silent sites contribute to postintegration latency $[21,22]$. Although there may not be a common mechanism that promotes HIV latency, it is critical to understand the molecular events that establish and maintain latency if strategies to reduce or purge HIV from latent reservoirs are to be devised $[9,23,24]$. HIV transcription is regulated at multiple levels including transcription initiation, polymerase recruitment, transcriptional elongation, and chromatin organization. How these events are coordinated and their role in HIV latency will be reviewed. In particular, mechanisms that contribute to repressing HIV transcription will be highlighted.

\section{LTR and Transcription Factors}

Although viral accessory proteins, such as Vpr, and putative elements within the HIV provirus genome may influence HIV transcription $[25,26]$, the dominant HIV transcriptional regulatory element is the $5^{\prime}$ long terminal repeat (LTR). The HIV LTR is often divided into four functional elements: the Tat activating region (TAR), which in the context of the nascent RNA forms an RNA stem loop structure that binds the virus-encoded transactivator Tat; the promoter, the enhancer, and the negative/modulatory regulatory element (Figure 1(a)). The promoter, enhancer and modulatory elements recruit a plethora of tissue specific and ubiquitously expressed host-transcription factors that function as activators, repressors, or adapter proteins (see references for detailed reviews [27-29]). AP- 1, Sp1, and NF- $\kappa$ B 
(a)
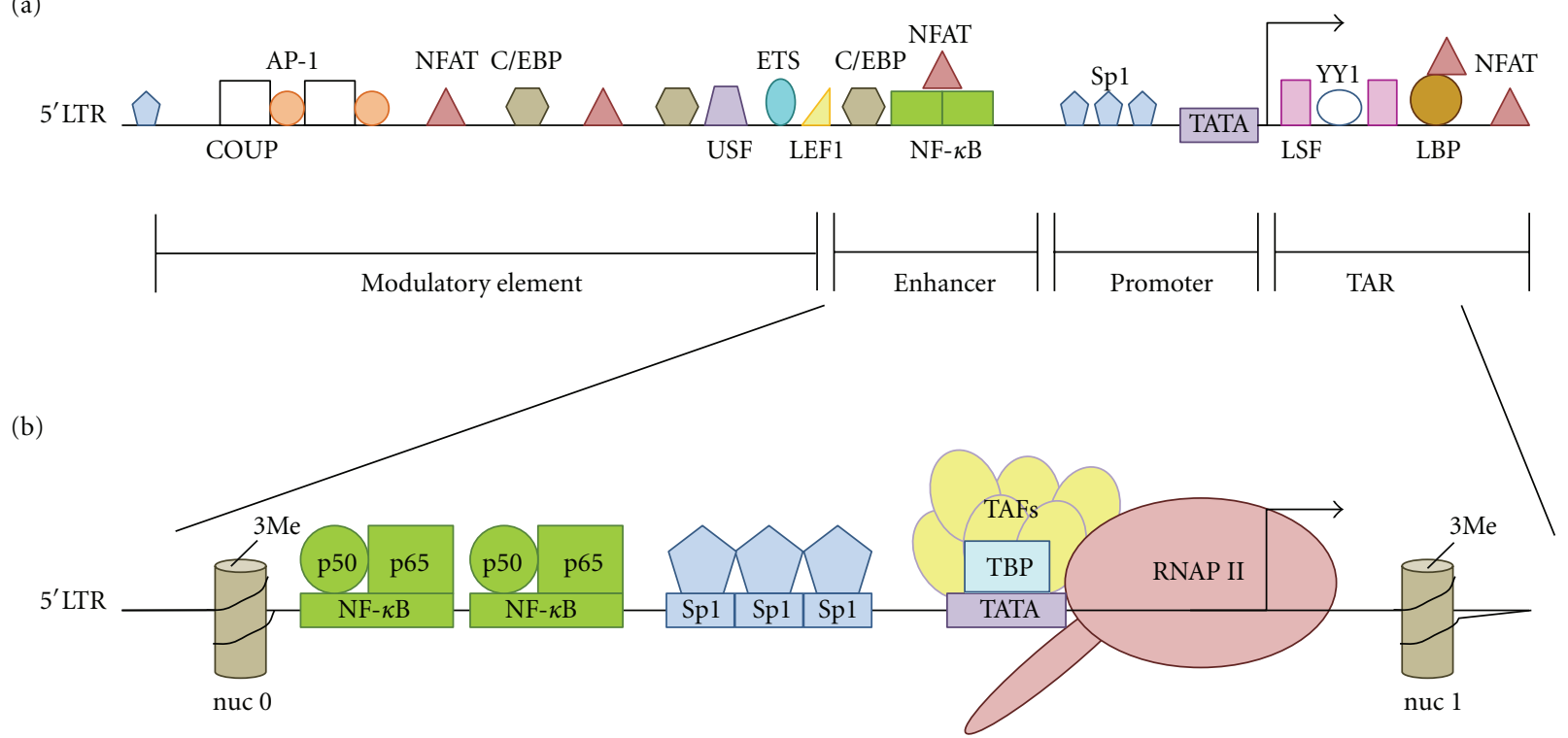

(c)

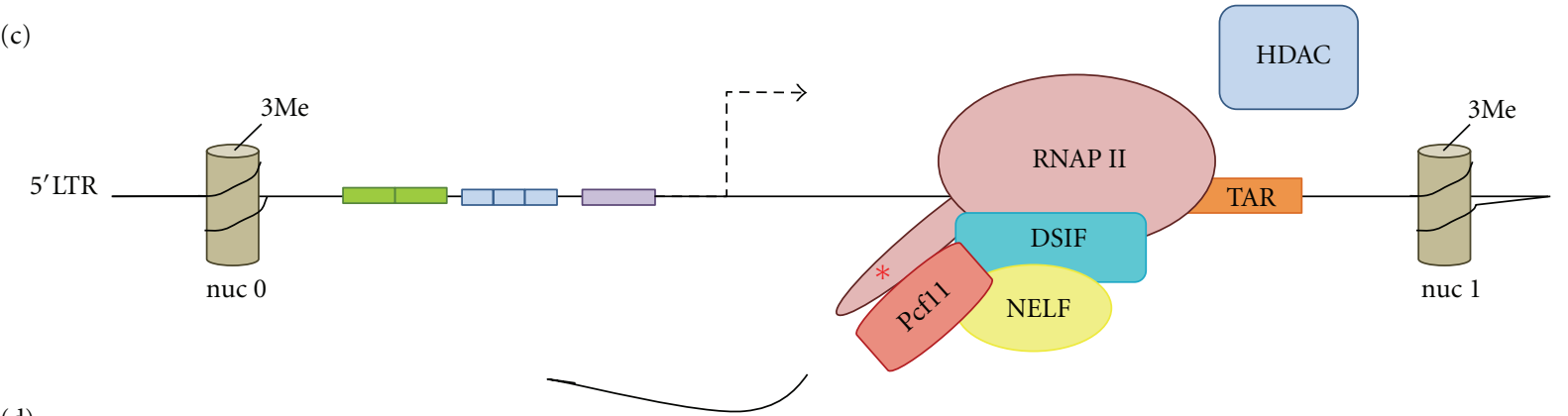

(d)

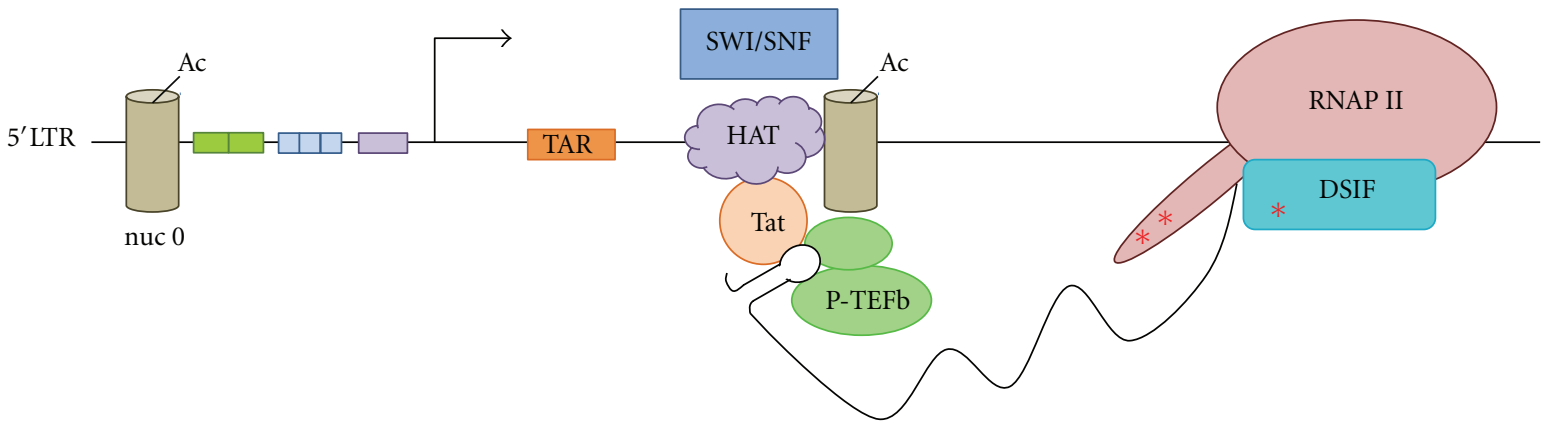

FIGURE 1: Regulation of HIV transcription initiation and elongation. (a) HIV LTR organization. This only represents a small subset of ciselements and transcription factors, which bind these sites. (b) Cellular transcription factors are recruited to LTR elements and initiation complex forms at the transcriptional start site. Nucleosomes are posttranslationally modified favoring a condensed chromatin structure that impedes RNAP II transcriptional elongation. (c) RNAP II processes a short distance downstream from the transcriptional start site when DSIF and NELF induce a pause in transcription. Pcf11 reinforces this block in elongation by prematurely terminating the transcription of the short nascent RNA product. HDAC recruitment to the paused complex reinforces a transcriptionally repressed chromatin state. The red asterisk depicts phosphorylation of RNAP II CTD at serine 5 position. (d) RNAP II elongation complex is released from the transcriptional pause by the recruitment of P-TEFb, which mediates hyperphosphorylation of the CTD at serine 2 position and phosphorylation of DSIF, which induces NELF disassociation from the complex (red asterisks indicate key phosphorylation events). The recruitment of chromatin remodeling machinery such as HATs and PBAF SWI/SNF facilitates acetylation of nucleosomes, which displaces the blocking nucleosome and supports transcription elongation.

are required for efficient basal and induced HIV transcription and replication [27-32]. One major check-point in the control of HIV transcription is the availability of critical transcription factors. Several inducible transcription factors have been identified in T cell and monocytic cell lines that transactivate the HIV LTR, including AP-1 [30, 33, 34], C/EBPb [35, 36], NFAT [37-39], Ets/PU.1 [40, 41], and TCF/LEF-1 $[42,43]$ to cite a select few. A classic example of 
transcription factor availability regulating function is the binding of NF- $\kappa$ B to sites within the HIV LTR [44]. Upon cell activation, the p65 subunit is released from the I $\kappa \mathrm{B}$ inhibitory complex, dimerizes with the p50 NF- $\kappa \mathrm{B}$ subunit, and translocates from the cytoplasm to the nucleus, where it binds the NF- $\kappa$ B sites in HIV LTR to mediate efficient transcription [17]. However, sequestering p65 in the cytoplasm through its interaction with $\mathrm{I} \kappa \mathrm{B}$ limits the availability of active NF- $\kappa \mathrm{B}$ in the nucleus and HIV provirus transcription. Furthermore, this transcriptional repression is reinforced by p50-p50 homodimers binding the NF- $\kappa \mathrm{B}$ sites and recruiting histone deacetylase complexes (HDACs), which promote a repressive chromatin state [18]. In addition, there have been reports of several cellular transcription factors that repress transcription in the context of HIV latency. They include but are not limited to, the ubiquitous factors LSF-1, YY-1 [45, 46]; Sp1 and the bHLH-zipper proto-oncogene c-Myc [47]; CTIP-2/Bcll11b, a COUP-TF interacting protein expressed in the central nervous system that interacts with Sp1 [48, 49]; CBF-1, an effector of Notch signaling that is regulated during $\mathrm{T}$ cell activation [50]; ligand-activated nuclear receptors [51]; FBI-1, a POZ domain, Kruppel-type zinc finger [52]. Which combination of these factors potentially establishes latency in specific cellular subsets is a critical question that needs to be addressed.

\section{Chromatin and HIV Transcription}

One function of transcription factors is to recruit complexes that influence chromatin organization. For example, transcriptional activators such as NF- $\kappa \mathrm{B}$, NFAT, and C/EBP $\beta$ recruit histone acetyltransferases (HATs) that modify key lysines on histone 3 and histone 4 [10, 24, 44, 53-56]. Histone acetylation, which is associated with active transcription, results in an open or accessible DNA conformation that is more amenable to the binding of additional transcriptional activators, initiation factors, and RNA polymerase II (RNAP II). SWI/SNF complexes and demethylases are recruited to promoters and enhancers by transcription factors and coactivators to remodel nucleosomes, especially around the promoter and transcriptional start sites of genes, resulting in the induction of transcription. The chromatin organization of the HIV LTR has been studied in detail (reviewed in [5557]). The HIV LTR is flanked by two positioned nucleosomes, nuc- 0 at the $5^{\prime}$ end of the LTR and nuc- 1 that is juxtaposed to the transcriptional start site (Figure 1(b)). Induction of HIV transcription correlates with histone acetylation, recruitment of HATs [53, 58-60], PBAF containing SWI/SNF complexes [61-64], and displacement of nuc-1 [57, 61, 63-67]. These posttranscriptional modifications to the chromatin state are associated with HIV transcription.

Reversing the posttranslational modifications associated with transcriptional activation is accomplished by recruiting SWI/SNF complexes, HDACs, and/or methyltransferases, which catalyze histone trimethylation. These inhibitory modifications are proposed to contribute to a more condensed chromatin structure which impedes RNAP II processivity and transcription elongation $[68,69]$. For SWI/SNF there are at least two distinctive complexes that have been described, PBAF which has been associated with transcriptional activation and BAF which has been implicated in the establishment and maintenance of HIV latency [62, 64]. Class I and II HDACs [54, 70], the methyltransferases Suv39H1, Zeste 2, and heterochromatin protein 1 (hp-1) [71, 72] have been implicated in mediating the deacetylation and trimethylation of nuc- 1 and the repression of HIV transcriptional elongation. Long term repression of transcription can be reinforced by additional epigenetic changes including DNA methylation $[55,73]$. In summary, posttranslational modifications of chromatin have been linked to the maintenance of latent viral reservoirs.

\section{Transcriptional Interference}

Although epigenetic events, such as restrictive positioned nucleosomes or DNA methylation, limit HIV transcription recent studies examining proviral integration sites have highlighted the need to consider additional models to explain repression of HIV transcription. Initial experiments by the Bushman laboratory [74-77] in which proviral integration sites in cells that were latently infected with HIV were sequenced indicated that silenced HIV preferentially integrated into transcriptionally active host genes. Similar findings were obtained in infection models with cell lines [77-80] and primary cells, as well as resting CD4 cells from patients either untreated or undergoing HAART $[79,81]$. These findings indicate that active neighboring promoters are directly repressing or transcriptionally interfering with the HIV LTR [78, $80,82]$. Transcriptional interference is defined as the suppression of one transcription unit by another neighboring cis-element [83]. Suggested mechanisms that lead to interference of the HIV LTR include the adjacent promoters competing for or displacing the components of transcription initiation complexes, or collisions between transcription elongation complexes moving in opposite directions [8388]. Although there may be a potential role for chromatinassociated factors in maintaining transcriptional interference [89], other reports from the literature would predict that there are additional critical repressive checkpoints that contribute to HIV latency [78, 82].

\section{Transcriptional Elongation}

Transcription factors assist with the recruitment of the general basal factors, which include the RNAP II itself, TFIID (TATA binding protein or TBP), and the TBPassociated factors (TAFs), TFIIA, TFIIB, TFIIE, TFIIF, and $\mathrm{TFIIH}$, to assemble the core promoter complex and assure proper positioning of the RNAP II at the transcriptional start site (Figure 1(b)). General transcription factors, such as TFIIH, have been implicated as playing a critical role in HIV transcription at times of low Tat expression [90]. However, recently, the concept of a "core" promoter has been challenged by the dis-covery of tissue-specific TAFs and unique preinitiation com-plexes [91] favoring models in which the factors found at core promoters and the 
RNAP II are diverse and dynamic. For example, RNAP II associated protein, Gdown1, competes with TFIIF for RNAP II, therefore inhibiting transcription and promoting the assembly of a paused RNAP II complex $[92,93]$. Whether the complexity associated with RNAP II recruitment and assembly reflects cell type and cell-cycle-specific requirements for HIV transcription is just starting to be investigated. However, it has been shown that Tat can influence the recruitment of TBP and associated TAFs [94] suggesting that these early transcriptional complexes are regulated by HIV infection.

Control of transcription elongation is a critical checkpoint in the regulation of a number of genes including c-myc, c-fms, hsp-70, Jun B, and HIV [95-99] and is dependent on the coordination of RNAP II activity, premature transcription termination, and chromatin structure [100]. Furthermore, several genome-wide studies with multiple organisms mapping RNAP II location have shown that $20-30 \%$ of genes have enriched RNAP II density at the $5^{\prime}$ end of the gene relative to the body of the gene. This was discovered for genes with both detectable or undetectable transcription [101104] suggesting that post-RNAP II recruitment and transcriptional elongation represents a key rate-limiting transcriptional checkpoint for gene expression [105]. The interplay between the negative elongation factors, negative elongation factor (NELF) and DRB sensitivity-inducing factor (DSIF), and positive elongation factors, such as $\mathrm{P}-\mathrm{TEFb}$ [106], sets this checkpoint. NELF and DSIF associate with the early elongation complex and inhibit RNAP II processivity, possibly by interfering with the extrusion of the nascent transcript from the elongation complex [107]. P-TEFb, which is composed of a regulatory Cyclin T1 (CycT1) subunit and an enzymatic Cyclin-dependent kinase 9 (Cdk9) subunit, alleviates transcriptional repression by phosphorylating one or more of the components in this complex as well as the carboxy terminal domain (CTD) of RNAP II at serine 2 leading to the active engagement of RNAP II in transcription elongation [108-112]. Phosphorylation of DSIF converts DSIF from a negative to a positive elongation factor [106], whereas phosphorylation of NELF by P-TEFb reduces the ability of NELF to associate with RNA [113]. Notably, NELF dissociates from the elongation complex when the complex is transcribing the DNA in vivo suggesting that NELF primarily functions as an inhibitor of elongation [114] (Figure 1).

$\mathrm{P}-\mathrm{TEFb}$ is a general transcription factor, which is required for efficient expression of the majority of cellular genes, and its availability and activity is carefully regulated to allow for changes in global transcriptional demand [115117]. The regulation of P-TEFb is complex and employs multiple transcriptional and posttranslational strategies that may impact HIV transcription as well as overall cellular gene expression. One mechanism that limits P-TEFb is its association with the 7SK complex, which includes 7SK RNA, HEXIM1, HEXIM2, MePCE, and LARP7 [55, 115-117]. Release of $\mathrm{P}-\mathrm{TEFb}$ from this complex during $\mathrm{T}$ cell activation favors enhanced HIV transcription. Furthermore, recent biochemical profiling has indicated that there are multiple P$\mathrm{TEFb}$ complexes that include association with other coactivators including Brd4 [118-120], SKIP [121, 122], and components of the super elongation complex $[116,123,124]$.
Although the significance of these different complexes with regard to HIV latency is still being explored, it is tempting to speculate that these additional cofactors could couple transcription elongation with other processes that influence gene expression including chromatin organization and splicing. P-TEFb activity is also regulated by phosphorylation and dephosyphorylation in the T-loop domain of Cdk9. Although the kinase responsible for Cdk9 posttranslational modification has not been reported, several phosphatases, PPM1, PP1, PP2A, PP2B have been implicated in regulating $\mathrm{P}-\mathrm{TEFb}$ and HIV transcription [125-129]. Finally, P-TEFb activity is in part regulated by expression of CycT1, which is regulated at a transcriptional level in macrophages and CD4+ $\mathrm{T}$ cells [130].

Recruitment of P-TEFb to the HIV LTR is a critical step for transcriptional activation and this is the primary function of the viral transcriptional activator Tat. Furthermore, NELF and DSIF, which are necessary for pausing RNAP II, are both bound to the HIV LTR after initiation of viral transcription $[110,113,131]$. The NELF E subunit, which has an RNA binding domain, has been shown to bind the HIV-TAR element and inhibit Tat transactivation [113, 132]. Diminishing the Spt5 subunit of DSIF decreases HIV replication [110], whereas decreasing NELF expression releases paused polymerases on the HIV LTR and induces HIV transcription elongation in cell line models for transcriptional latency. In addition, depleting NELF induced histone acetylation and displacement of the positioned nucleosome, hinting that transcription elongation and chromatin remodeling maybe coupled processes [131].

In the context of HIV, RNAP II processivity and transcriptional elongation are highly regulated events as suggested by the accumulation of short transcripts in the cytoplasm in HIV-infected cells [96-98, 133]. Under conditions that inhibit transcription elongation, RNAP II is prone to premature termination which reenforces the block in RNAP II processivity and the accumulation of short transcripts observed in cells that have repressed HIV provirus. One possibility for this is that a termination complex is recruited to RNAP II, which destabilizes the nonprocessive RNAP II complex similar to $3^{\prime}$ end processing of mRNA and transcription termination. Only two proteins are known that have the capa-city to dissociate RNAP II from the DNA template: TTF2, which dissociates the elongation complex in an ATPdependent manner during chromosome condensation of the M-phase of the cell cycle [134] and Pcf11, which is involved in $3^{\prime}$ end processing of mRNA and transcription termination of protein-encoding genes $[135,136]$. Pcf11 has been demonstrated to dissociate transcriptionally engaged RNAP II from DNA, indicating a pivotal role in termination [137-139]. Recent reports show that Pcf11 binds to the HIV LTR and represses HIV transcription in cell line models for HIV latency [140]. Pcf11 may be recruited to the LTR by the paused RNAP II complex. In summary, HIV transcriptional elongation is limited by multiple mechanisms that include the availability of P-TEFb, processiveness of the RNAP II complex, and premature termination (Figure 1(c)). 


\section{Tat}

The presence of a blocking nucleosome and the role of pausing and premature termination would indicate that transcriptional elongation presents a major checkpoint to HIV transcription. HIV overcomes this limitation through the function of the virally encoded transcriptional activator Tat. Tat potently activates HIV gene expression by facilitating the recruitment of $\mathrm{P}-\mathrm{TEFb}$ to the HIV LTR. Tat binds the RNA stem loop structure formed by the TAR element and recruits $\mathrm{P}-\mathrm{TEFb}$ through its interaction with the CycT1 subunit [141]. The Tat-P-TEFb interaction brings active Cdk9 into the proximity of the paused RNAP II complex. $\mathrm{P}-\mathrm{TEFb}$ phosphorylates the CTD domain of RNAP II as well as NELF and DSIF, inducing RNAP II processivity and transcriptional elongation. In addition to directly targeting the paused RNAP II complex Tat recruits chromatin remodeling factors such as SWI/SNF complexes Brm and/or Brg-1 $[63,64,142]$ as well as HATs, p300/CBP, P/CAF and GCN5 that can promote transcriptional activation through post-translational modification of histones and the remodeling of the positioned nuc-1 [59, 63]. Thus, Tat is positioned to play a cri-tical role in coordinating transcriptional elongation and chromatin remodeling to assure efficient HIV transcription. The transactivation of Tat couples HIV transcriptional elon-gation along with chromatin remodeling [21, 67] (Figure 1(d)).

Tat activity is regulated at multiple levels including transcription and posttranslational modification [143]. Tat transcription is regulated by the HIV LTR and if repressed, limited Tat will be expressed. Minimal Tat function, either due to lack of cellular factors or mutation to the Tat-TAR axis, favors repression of HIV transcription and latency [55, 143]. In addition, stochastic fluctuations in Tat transcription have been shown to overcome initial repression and induce efficient transcription elongation [144]. Post-translational modifications of Tat have been demonstrated to modulate its interactions with TAR, P-TEFb, and chromatin-remodeling complexes to assure the transactivation of Tat even under limiting conditions [145]. In particular, Tat is subject to a dynamic sequential methylation/demethylation and acetylation/deacetylation cycles. Monomethylation of lysine 51 (K51) by Set7/9/KMT7 enhances Tat binding to the TAR, whereas demethylation by LSD1/KDM1/CoREST and acetylation of neighboring lysine 50 (K50) mediated by p300/ KAT3B favor the dissociation of Tat from TAR and P-TEFb [146-150]. SIRT1, the class III nicotinamide adenine dinucleotide-dependent class III protein, deacetylates Tat and represses its activity [149]. The methyltransferase, demethylase HDACs and HATS that control HIV Tat function are attractive therapeutic targets [150].

\section{Conclusion and Implications}

Studies using a variety of cell lines $[16,22,151]$ and primary cell systems [37, 152, 153] have provided insights into the complexity of HIV transcription and the appreciation that multiple mechanisms contribute to latency [154]. Furthermore, these studies have suggested that therapeutic strategies targeting transcription may be used to purge HIV from different cellular reservoirs. Attempts to activate repressed proviral transcription present several unique challenges including the lack of a single or common event in establishment and maintenance of latency, and most factors that limit HIV transcription are general transcriptional regulators and cofactors, which are necessary for normal gene expression. Compounds that target RNAP II, P-TEFb, and chromatin remodeling factors will likely be toxic, lack specificity, and have a global impact on gene expression. The challenges that exist in translating our general understanding of HIV transcription into a viable therapeutic approach are highlighted by the recent clinical trials with HDAC inhibitors. Based on the strong evidence from cell line models of HIV latency, which showed that overcoming the repressive effects of chromatin induces HIV transcription, it was hypothesized that HDAC inhibitors could be a useful tool in purging HIV from latently infected cells [155]. Initial experiments using the HDAC inhibitor valproic acid with primary cells from HIV-positive patients were encouraging [156-158]; however, follow-up studies and a recent clinical trial have shown that valproic acid had a minimal impact on the low level of virema in the peripheral blood of ART patients [159-163]. Although these results might be viewed as discouraging, next-generation HDAC inhibitors $[164,165]$ in combination with other potential treatments such as methyltransferase inhibitors [166] as well as newly identified compounds discovered in recent screens $[89,153]$, which target HIV transcription but only partially activate T cells, may be efficacious. As we screen and develop new compounds, it will be critical to assure that they are active in multiple in vitro and in vivo models of latency to assure that the broad range of potential mechanisms that influence HIV transcription and latency are targeted [154].

\section{Acknowledgments}

The authors thank Dr. David Gilmour, Penn State University, and members of the Henderson Laboratory for critical discussion. This work was in part supported by NIH AI097117, awarded to A. J. Henderson.

\section{References}

[1] S. G. Deeks, T. Wrin, T. Liegler et al., "Virologic and immunologic consequences of discontinuing combination antiretroviral-drug therapy in HIV-infected patients with detectable viremia," The New England Journal of Medicine, vol. 344, no. 7, pp. 472-480, 2001.

[2] A. Noë, J. Plum, and C. Verhofstede, "The latent HIV-1 reservoir in patients undergoing HAART: an archive of preHAART drug resistance," Journal of Antimicrobial Chemotherapy, vol. 55, no. 4, pp. 410-412, 2005.

[3] D. Persaud, T. Pierson, C. Ruff et al., "A stable latent reservoir for HIV-1 in resting CD4 $4^{+} \mathrm{T}$ lymphocytes in infected children," Journal of Clinical Investigation, vol. 105, no. 7, pp. 9951003, 2000.

[4] C. T. Ruff, S. C. Ray, P. Kwon et al., "Persistence of wild-type virus and lack of temporal structure in the latent reservoir for human immunodeficiency virus type 1 in pediatric patients 
with extensive antiretroviral exposure," Journal of Virology, vol. 76, no. 18, pp. 9481-9492, 2002.

[5] T. W. Chun, L. Carruth, D. Finzi et al., "Quantification of latent tissue reservoirs and total body viral load in HIV-1 infection," Nature, vol. 387, no. 6629, pp. 183-188, 1997.

[6] T. W. Chun, L. Stuyver, S. B. Mizell et al., "Presence of an inducible HIV-1 latent reservoir during highly active antiretroviral therapy," Proceedings of the National Academy of Sciences of the United States of America, vol. 94, no. 24, pp. 13193-13197, 1997.

[7] D. Finzi, M. Hermankova, T. Pierson et al., "Identification of a reservoir for HIV-1 in patients on highly active antiretroviral therapy," Science, vol. 278, no. 5341, pp. 1295-1300, 1997.

[8] J. K. Wong, M. Hezareh, H. F. Günthard et al., "Recovery of replication-competent HIV despite prolonged suppression of plasma viremia," Science, vol. 278, no. 5341, pp. 1291-1295, 1997.

[9] T. W. Chun and A. S. Fauci, "Latent reservoirs of HIV: obstacles to the eradication of virus," Proceedings of the National Academy of Sciences of the United States of America, vol. 96, no. 20, pp. 10958-10961, 1999.

[10] T. Pierson, J. McArthur, and R. F. Siliciano, "Reservoirs for HIV-1: mechanisms for viral persistence in the presence of antiviral immune responses and antiretroviral therapy," Annual Review of Immunology, vol. 18, pp. 665-708, 2000.

[11] C. C. Carter, A. Onafuwa-Nuga, L. A. McNamara et al., "HIV1 infects multipotent progenitor cells causing cell death and establishing latent cellular reservoirs," Nature Medicine, vol. 16, no. 4, pp. 446-451, 2010.

[12] C. M. Durand, G. Ghiaur, J. D. Siliciano et al., "HIV-1 DNA is detected in bone marrow populations containing $\mathrm{CD} 4^{+} \mathrm{T}$ cells but is not found in purified $\mathrm{CD} 34^{+}$hematopoietic progenitor cells in most patients on antiretroviral therapy," The Journal of Infectious Diseases, vol. 205, no. 6, pp. 1014-1018, 2012.

[13] S. Emiliani, W. Fischle, M. Ott, C. Van Lint, C. A. Amella, and E. Verdin, "Mutations in the tat gene are responsible for human immunodeficiency virus type 1 postintegration latency in the U1 cell line," Journal of Virology, vol. 72, no. 2, pp. 1666-1670, 1998.

[14] S. Yukl, S. Pillai, P. Li et al., "Latently-infected CD4+ T cells are enriched for HIV-1 Tat variants with impaired transactivation activity," Virology, vol. 387, no. 1, pp. 98-108, 2009.

[15] R. M. van der Sluis, G. Pollakis, M. L. van Gerven, B. Berkhout, and R. E. Jeeninga, "Latency profiles of full length HIV-1 molecular clone variants with a subtype specific promoter," Retrovirology, vol. 8, p. 73, 2011.

[16] T. M. Folks, J. Justement, A. Kinter et al., "Characterization of a promonocyte clone chronically infected with HIV and inducible by 13-phorbol-12-myristate acetate," Journal of Immunology, vol. 140, no. 4, pp. 1117-1122, 1988.

[17] G. Nabel and D. Baltimore, "An inducible transcription factor activates expression of human immunodeficiency virus in $\mathrm{T}$ cells," Nature, vol. 326, no. 6114, pp. 711-713, 1987.

[18] S. A. Williams, L. F. Chen, H. Kwon, C. M. Ruiz-Jarabo, E. Verdin, and W. C. Greene, "NF- $\kappa$ B p50 promotes HIV latency through HDAC recruitment and repression of transcriptional initiation," The EMBO Journal, vol. 25, no. 1, pp. 139-149, 2006.

[19] A. Narayanan, K. Kehn-Hall, C. Bailey, and F. Kashanchi, "Analysis of the roles of HIV-derived microRNAs," Expert Opinion on Biological Therapy, vol. 11, no. 1, pp. 17-29, 2011.
[20] R. Triboulet, B. Mari, Y. L. Lin et al., "Suppression of MicroRNA-silencing pathway by HIV-1 during virus replication," Science, vol. 315, no. 5818, pp. 1579-1582, 2007.

[21] A. Jordan, D. Bisgrove, and E. Verdin, "HIV reproducibly establishes a latent infection after acute infection of $\mathrm{T}$ cells in vitro," The EMBO Journal, vol. 22, no. 8, pp. 1868-1877, 2003.

[22] A. Jordan, P. Defechereux, and E. Verdin, "The site of HIV-1 integration in the human genome determines basal transcriptional activity and response to Tat transactivation," The EMBO Journal, vol. 20, no. 7, pp. 1726-1738, 2001.

[23] R. Pearson, K. K. Young, J. Hokello et al., "Epigenetic silencing of human immunodeficiency virus (HIV) transcription by formation of restrictive chromatin structures at the viral long terminal repeat drives the progressive entry of HIV into latency," Journal of Virology, vol. 82, no. 24, pp. 12291-12303, 2008.

[24] R. F. Siliciano and W. C. Greene, "HIV latency," Cold Spring Harbor Perspectives in Medicine, vol. 1, Article ID a007096, 2011.

[25] M. Kogan and J. Rappaport, "HIV-1 accessory protein Vpr: relevance in the pathogenesis of HIV and potential for therapeutic intervention," Retrovirology, vol. 8, article 25, 2011.

[26] M. D. Marsden, B. P. Burke, and J. A. Zack, "HIV latency is influenced by regions of the viral genome outside of the long terminal repeats and regulatory genes," Virology, vol. 417, pp. 394-399, 2011.

[27] E. M. Kilareski, S. Shah, M. R. Nonnemacher, and B. Wigdahl, "Regulation of HIV-1 transcription in cells of the monocyte-macrophage lineage," Retrovirology, vol. 6, article $118,2009$.

[28] L. A. Pereira, K. Bentley, A. Peeters, M. J. Churchill, and N. J. Deacon, "A compilation of cellular transcription factor interactions with the HIV-1 LTR promoter," Nucleic Acids Research, vol. 28, no. 3, pp. 663-668, 2000.

[29] O. Rohr, C. Marban, D. Aunis, and E. Schaeffer, "Regulation of HIV-1 gene transcription: from lymphocytes to microglial cells," Journal of Leukocyte Biology, vol. 74, no. 5, pp. 736-749, 2003.

[30] Y. Li, G. Mak, and B. R. Franza Jr., "In vitro study of functional involvement of Sp1, NF- $\kappa \mathrm{B} / \mathrm{Rel}$, and AP1 in phorbol 12-myristate 13-acetate-mediated HIV-1 long terminal repeat activation," Journal of Biological Chemistry, vol. 269, no. 48, pp. 30616-30619, 1994.

[31] B. Majello, P. De Luca, G. Hagen, G. Suske, and L. Lania, "Different members of the Sp1 multigene family exert opposite transcriptional regulation of the long terminal repeat of HIV1," Nucleic Acids Research, vol. 22, no. 23, pp. 4914-4921, 1994.

[32] N. D. Perkins, N. L. Edwards, C. S. Duckett, A. B. Agranoff, R. M. Schmid, and G. J. Nabel, "A cooperative interaction between NF- $\kappa$ B and $S p 1$ is required for HIV-1 enhancer activation," The EMBO Journal, vol. 12, no. 9, pp. 3551-3558, 1993.

[33] F. Canonne-Hergaux, D. Aunis, and E. Schaeffer, "Interactions of the transcription factor AP-1 with the long terminal repeat of different human immunodeficiency virus type 1 strains in Jurkat, glial, and neuronal cells," Journal of Virology, vol. 69, no. 11, pp. 6634-6642, 1995.

[34] K. A. Roebuck, S. De Gu, and M. F. Kagnoff, "Activating protein-1 cooperates with phorbol ester activation signals to increase HIV-1 expression," AIDS, vol. 10, no. 8, pp. 819-826, 1996. 
[35] A. J. Henderson, R. I. Connor, and K. L. Calame, "C/EBP activators are required for HIV-1 replication and proviral induction in monocytic cell lines," Immunity, vol. 5, no. 1, pp. 91-101, 1996.

[36] V. M. Tesmer, A. Rajadhyaksha, J. Babin, and M. Bina, "NF-IL6-mediated transcriptional activation of the long terminal repeat of the human immunodeficiency virus type 1," Proceedings of the National Academy of Sciences of the United States of America, vol. 90, no. 15, pp. 7298-7302, 1993.

[37] A. Bosque and V. Planelles, "Induction of HIV-1 latency and reactivation in primary memory $\mathrm{CD}^{+} \mathrm{T}$ cells," Blood, vol. 113, no. 1, pp. 58-65, 2009.

[38] R. Q. Cron, S. R. Bartz, A. Clausell, S. J. Bort, S. J. Klebanoff, and D. B. Lewis, "NFAT1 enhances HIV-1 gene expression in primary human CD4 T cells," Clinical Immunology, vol. 94, no. 3, pp. 179-191, 2000.

[39] J. F. Fortin, B. Barbeau, G. A. Robichaud, M. È. Paré, A. M. Lemieux, and M. J. Tremblay, "Regulation of nuclear factor of activated T cells by phosphotyrosyl-specific phosphatase activity: a positive effect on HIV-1 long terminal repeat-driven transcription and a possible implication of SHP-1," Blood, vol. 97, no. 8, pp. 2390-2400, 2001.

[40] T. A. Lodie, M. Reiner, S. Coniglio, G. Viglianti, and M. J. Fenton, "Both PU.1 and nuclear factor- $\kappa$ B mediate lipopolysaccharide-induced HIV-1 long terminal repeat transcription in macrophages," Journal of Immunology, vol. 161, no. 1, pp. 268-276, 1998.

[41] C. Van Lint, J. Ghysdael, P. Paras, A. Burny, and E. Verdin, "A transcriptional regulatory element is associated with a nuclease- hypersensitive site in the pol gene of human immunodeficiency virus type 1," Journal of Virology, vol. 68, no. 4, pp. 2632-2648, 1994.

[42] D. Carroll-Anzinger, A. Kumar, V. Adarichev, F. Kashanchi, and L. Al-Harthi, "Human immunodeficiency virus-restricted replication in astrocytes and the ability of gamma interferon to modulate this restriction are regulated by a downstream effector of the Wnt signaling pathway," Journal of Virology, vol. 81, no. 11, pp. 5864-5871, 2007.

[43] B. Wortman, N. Darbinian, B. E. Sawaya, K. Khalili, and S. Amini, "Evidence for regulation of long terminal repeat transcription by Wnt transcription factor TCF-4 in human astrocytic cells," Journal of Virology, vol. 76, no. 21, pp. 11159-11165, 2002.

[44] J. K. Chan and W. C. Greene, "NF- $\kappa$ B/Rel: agonist and antagonist roles in HIV-1 latency," Current Opinion in HIV and AIDS, vol. 6, no. 1, pp. 12-18, 2011.

[45] L. Ylisastigui, R. Kaur, H. Johnson et al., "Mitogen-activated protein kinases regulate LSF occupancy at the human immunodeficiency virus type 1 promoter," Journal of Virology, vol. 79, no. 10, pp. 5952-5962, 2005.

[46] F. Romerio, M. N. Gabriel, and D. M. Margolis, "Repression of human immunodeficiency virus type 1 through the novel cooperation of human factors YY1 and LSF," Journal of Virology, vol. 71, no. 12, pp. 9375-9382, 1997.

[47] G. Jiang, A. Espeseth, D. J. Hazuda, and D. M. Margolis, "c-Myc and Spl contribute to proviral latency by recruiting histone deacetylase 1 to the human immunodeficiency virus type 1 promoter," Journal of Virology, vol. 81, no. 20, pp. 10914-10923, 2007.

[48] V. B. Cismasiu, E. Paskaleva, S. Suman Daya, M. Canki, K. Duus, and D. Avram, "BCL11B is a general transcriptional repressor of the HIV-1 long terminal repeat in T lymphocytes through recruitment of the NuRD complex," Virology, vol. 380 , no. 2, pp. 173-181, 2008.
[49] C. Marban, S. Suzanne, F. Dequiedt et al., "Recruitment of chromatin-modifying enzymes by CTIP2 promotes HIV-1 transcriptional silencing," The EMBO Journal, vol. 26, no. 2, pp. 412-423, 2007.

[50] M. Tyagi and J. Karn, "CBF-1 promotes transcriptional silencing during the establishment of HIV-1 latency," The EMBO Journal, vol. 26, no. 24, pp. 4985-4995, 2007.

[51] T. M. Hanley and G. A. Viglianti, "Nuclear receptor signaling inhibits HIV-1 replication in macrophages through multiple trans-repression mechanisms," Journal of Virology, vol. 85, no. 20, pp. 10834-10850, 2011.

[52] D. J. Morrison, P. S. Pendergrast, P. Stavropoulos, S. U. Colmenares, R. Kobayashi, and N. Hernandez, "FBI-1, a factor that binds to the HIV-1 inducer of short transcripts (IST), is a POZ domain protein," Nucleic Acids Research, vol. 27, no. 5, pp. 1251-1262, 1999.

[53] E. S. Lee, D. Sarma, H. Zhou, and A. J. Henderson, "CCAAT/ enhancer binding proteins are not required for HIV-1 entry but regulate proviral transcription by recruiting coactivators to the long-terminal repeat in monocytic cells," Virology, vol. 299, no. 1, pp. 20-31, 2002.

[54] D. M. Margolis, "Histone deacetylase inhibitors and HIV latency," Current Opinion in HIV and AIDS, vol. 6, no. 1, pp. 25-29, 2011.

[55] U. Mbonye and J. Karn, "Control of HIV latency by epigenetic and non-epigenetic mechanisms," Current HIV Research, vol. 9, no. 8, pp. 554-567, 2011.

[56] D. D. Richman, D. M. Margolis, M. Delaney, W. C. Greene, D. Hazuda, and R. J. Pomerantz, "The challenge of finding a cure for HIV infection," Science, vol. 323, no. 5919, pp. 13041307,2009

[57] C. Van Lint, S. Emiliani, M. Ott, and E. Verdin, "Transcriptional activation and chromatin remodeling of the HIV-1 promoter in response to histone acetylation," The EMBO Journal, vol. 15, no. 5, pp. 1112-1120, 1996.

[58] M. Benkirane, R. F. Chun, H. Xiao et al., "Activation of integrated provirus requires histone acetyltransferase: p300 and P/CAF are coactivators for HIV-1 Tat," Journal of Biological Chemistry, vol. 273, no. 38, pp. 24898-24905, 1998.

[59] A. Pumfery, L. Deng, A. Maddukuri et al., "Chromatin remodeling and modification during HIV-1 Tat-activated transcription," Current HIV Research, vol. 1, no. 3, pp. 343362, 2003.

[60] D. J. Steger, A. Eberharter, S. John, P. A. Grant, and J. L. Workman, "Purified histone acetyltransferase complexes stimulate HIV-1 transcription from preassembled nucleosomal arrays," Proceedings of the National Academy of Sciences of the United States of America, vol. 95, no. 22, pp. 12924-12929, 1998.

[61] E. Agbottah, L. Deng, L. O. Dannenberg, A. Pumfery, and F. Kashanchi, "Effect of SWI/SNF chromatin remodeling complex on HIV-1 Tat activated transcription," Retrovirology, vol. 3, article 48, 2006.

[62] R. Easley, L. Carpio, L. Dannenberg et al., "Transcription through the HIV-1 nucleosomes: effects of the PBAF complex in Tat activated transcription," Virology, vol. 405, no. 2, pp. 322-333, 2010.

[63] T. Mahmoudi, M. Parra, R. G. J. Vries et al., "The SWI/SNF chromatin-remodeling complex is a cofactor for Tat transactivation of the HIV promoter," Journal of Biological Chemistry, vol. 281, no. 29, pp. 19960-19968, 2006.

[64] C. Tréand, I. du Chéné, V. Brès et al., "Requirement for SWI/SNF chromatin-remodeling complex in Tat-mediated activation of the HIV-1 promoter," The EMBO Journal, vol. 25, no. 8, pp. 1690-1699, 2006. 
[65] P. L. Sheridan, T. P. Mayall, E. Verdin, and K. A. Jones, "Histone acetyltransferases regulate HIV-1 enhancer activity in vitro," Genes and Development, vol. 11, no. 24, pp. 3327-3340, 1997.

[66] E. Verdin, P. Paras Jr., and C. Van Lint, "Chromatin disruption in the promoter of human immunodeficiency virus type 1 during transcriptional activation," The EMBO Journal, vol. 12, no. 8, pp. 3249-3259, 1993.

[67] A. El Kharroubi, G. Piras, R. Zensen, and M. A. Martin, "Transcriptional activation of the integrated chromatinassociated human immunodeficiency virus type 1 promoter," Molecular and Cellular Biology, vol. 18, no. 5, pp. 2535-2544, 1998.

[68] M. G. Izban and D. S. Luse, "Transcription on nucleosomal templates by RNA polymerase II in vitro: inhibition of elongation with enhancement of sequence-specific pausing," Genes and Development, vol. 5, no. 4, pp. 683-696, 1991.

[69] J. L. Workman and R. G. Roeder, "Binding of transcription factor TFIID to the major late promoter during in vitro nucleosome assembly potentiates subsequent initiation by RNA polymerase II," Cell, vol. 51, no. 4, pp. 613-622, 1987.

[70] K. S. Keedy, N. M. Archin, A. T. Gates, A. Espeseth, D. J. Hazuda, and D. M. Margolis, "A limited group of class I histone deacetylases acts to repress human immunodeficiency virus type 1 expression," Journal of Virology, vol. 83, no. 10, pp. 4749-4756, 2009.

[71] I. D. Chéné, E. Basyuk, Y. L. Lin et al., "Suv39H1 and HP1 $\gamma$ are responsible for chromatin-mediated HIV-1 transcriptional silencing and post-integration latency," The EMBO Journal, vol. 26, no. 2, pp. 424-435, 2007.

[72] J. Friedman, W. K. Cho, C. K. Chu et al., "Epigenetic silencing of HIV-1 by the histone H3 lysine 27 methyltransferase enhancer of Zeste 2," Journal of Virology, vol. 85, no. 17, pp. 9078-9089, 2011.

[73] S. E. Kauder, A. Bosque, A. Lindqvist, V. Planelles, and E. Verdin, "Epigenetic regulation of HIV-1 latency by cytosine methylation," Plos Pathogens, vol. 5, no. 6, Article ID e1000495, 2009.

[74] F. Bushman, M. Lewinski, A. Ciuffi et al., "Genome-wide analysis of retroviral DNA integration," Nature Reviews Microbiology, vol. 3, no. 11, pp. 848-858, 2005.

[75] M. K. Lewinski, D. Bisgrove, P. Shinn et al., "Genome-wide analysis of chromosomal features repressing human immunodeficiency virus transcription," Journal of Virology, vol. 79, no. 11, pp. 6610-6619, 2005.

[76] M. K. Lewinski, M. Yamashita, M. Emerman et al., "Retroviral DNA integration: viral and cellular determinants of target-site selection," Plos Pathogens, vol. 2, no. 6, p. e60, 2006.

[77] A. R. W. Schröder, P. Shinn, H. Chen, C. Berry, J. R. Ecker, and F. Bushman, "HIV-1 integration in the human genome favors active genes and local hotspots," Cell, vol. 110, no. 4, pp. 521-529, 2002.

[78] A. Duverger, J. Jones, J. May et al., "Determinants of the establishment of human immunodeficiency virus type 1 latency," Journal of Virology, vol. 83, no. 7, pp. 3078-3093, 2009.

[79] Y. Han, K. Lassen, D. Monie et al., "Resting CD4+ T cells from human immunodeficiency virus type 1 (HIV-1)-infected individuals carry integrated HIV-1 genomes within actively transcribed host genes," Journal of Virology, vol. 78, no. 12, pp. 6122-6133, 2004.

[80] Y. Han, Y. B. Lin, W. An et al., "Orientation-dependent regulation of integrated HIV-1 expression by host gene transcriptional readthrough," Cell Host and Microbe, vol. 4, no. 2, pp. 134-146, 2008.
[81] H. Liu, E. C. Dow, R. Arora et al., "Integration of human immunodeficiency virus type 1 in untreated infection occurs preferentially within genes," Journal of Virology, vol. 80, no. 15, pp. 7765-7768, 2006.

[82] T. Lenasi, X. Contreras, and B. M. Peterlin, “Transcriptional interference antagonizes proviral gene expression to promote HIV latency," Cell Host and Microbe, vol. 4, no. 2, pp. 123133, 2008.

[83] K. E. Shearwin, B. P. Callen, and J. B. Egan, "Transcriptional interference-a crash course," Trends in Genetics, vol. 21, no. 6, pp. 339-345, 2005.

[84] S. Adhya and M. Gottesman, "Promoter occlusion: transcription through a promoter may inhibit its activity," Cell, vol. 29, no. 3, pp. 939-944, 1982.

[85] B. P. Callen, K. E. Shearwin, and J. B. Egan, “Transcriptional interference between convergent promoters caused by elongation over the promoter," Molecular Cell, vol. 14, no. 5, pp. 647-656, 2004.

[86] S. K. Eszterhas, E. E. Bouhassira, D. I. K. Martin, and S. Fiering, "Transcriptional interference by independently regulated genes occurs in any relative arrangement of the genes and is influenced by chromosomal integration position," Molecular and Cellular Biology, vol. 22, no. 2, pp. 469-479, 2002.

[87] I. H. Greger, F. Demarchi, M. Giacca, and N. J. Proudfoot, "Transcriptional interference perturbs the binding of Sp1 to the HIV-1 promoter," Nucleic Acids Research, vol. 26, no. 5, pp. 1294-1300, 1998.

[88] S. Petruk, Y. Sedkov, K. M. Riley et al., "Transcription of bxd noncoding RNAs promoted by trithorax represses $\mathrm{Ubx}$ in cis by transcriptional interference," Cell, vol. 127, no. 6, pp. 1209-1221, 2006.

[89] E. Gallastegui, B. Marshall, D. Vidal et al., "Combination of biological screening in a cellular model of viral latency and virtual screening identifies novel compounds that reactivate HIV-1," Journal of Virology, vol. 86, no. 7, pp. 3795-3808, 2012.

[90] Y. K. Kim, C. F. Bourgeois, R. Pearson et al., "Recruitment of TFIIH to the HIV LTR is a rate-limiting step in the emergence of HIV from latency," The EMBO Journal, vol. 25, no. 15, pp. 3596-3604, 2006.

[91] J. A. D’Alessio, K. J. Wright, and R. Tjian, "Shifting players and paradigms in cell-specific transcription," Molecular Cell, vol. 36, no. 6, pp. 924-931, 2009.

[92] J. M. Espinosa, “Get back TFIIF, don't let me Gdown1,” Molecular Cell, vol. 45, pp. 3-5, 2012.

[93] M. Jishage, S. Malik, U. Wagner et al., "Transcriptional regulation by Pol II $(\mathrm{G})$ involving mediator and competitive interactions of Gdown 1 and TFIIF with Pol II," Molecular Cell, vol. 45, pp. 51-63, 2012.

[94] T. Raha, S. W. Cheng, and M. R. Green, "HIV-1 Tat stimulates transcription complex assembly through recruitment of TBP in the absence of TAFs," Plos Biology, vol. 3, no. 2, article e44, 2005.

[95] M. Aida, Y. Chen, K. Nakajima, Y. Yamaguchi, T. Wada, and H. Handa, "Transcriptional pausing caused by NELF plays a dual role in regulating immediate-early expression of the junB gene," Molecular and Cellular Biology, vol. 26, no. 16, pp. 6094-6104, 2006.

[96] M. B. Feinberg, D. Baltimore, and A. D. Frankel, "The role of Tat in the human immunodeficiency virus life cycle indicates a primary effect on transcriptional elongation," Proceedings of the National Academy of Sciences of the United States of America, vol. 88, no. 9, pp. 4045-4049, 1991. 
[97] S. Y. Kao, A. F. Calman, P. A. Luciw, and B. M. Peterlin, "Antitermination of transcription within the long terminal repeat of HIV-1 by tat gene product," Nature, vol. 330, no. 6147, pp. 489-493, 1987.

[98] M. F. Laspia, A. P. Rice, and M. B. Mathews, "HIV-1 Tat protein increases transcriptional initiation and stabilizes elongation," Cell, vol. 59, no. 2, pp. 283-292, 1989.

[99] J. Lis, "Promoter-associated pausing in promoter architecture and postinitiation transcriptional regulation," Cold Spring Harbor Symposia on Quantitative Biology, vol. 63, pp. 347$356,1998$.

[100] R. Landick, "The regulatory roles and mechanism of transcriptional pausing," Biochemical Society Transactions, vol. 34, no. 6, pp. 1062-1066, 2006.

[101] M. G. Guenther, S. S. Levine, L. A. Boyer, R. Jaenisch, and R. A. Young, "A chromatin landmark and transcription initiation at most promoters in human cells," Cell, vol. 130, no. 1, pp. 77-88, 2007.

[102] T. H. Kim, L. O. Barrera, M. Zheng et al., "A high-resolution map of active promoters in the human genome," Nature, vol. 436, no. 7052, pp. 876-880, 2005.

[103] G. W. Muse, D. A. Gilchrist, S. Nechaev et al., "RNA polymerase is poised for activation across the genome," Nature Genetics, vol. 39, no. 12, pp. 1507-1511, 2007.

[104] J. Zeitlinger, A. Stark, M. Kellis et al., "RNA polymerase stalling at developmental control genes in the Drosophila melanogaster embryo," Nature Genetics, vol. 39, no. 12, pp. 15121516, 2007.

[105] L. J. Core and J. T. Lis, "Transcription regulation through promoter-proximal pausing of RNA polymerase II," Science, vol. 319, no. 5871, pp. 1791-1792, 2008.

[106] T. Yamada, Y. Yamaguchi, N. Inukai, S. Okamoto, T. Mura, and H. Handa, "P-TEFb-mediated phosphorylation of hSpt5 C-terminal repeats is critical for processive transcription elongation," Molecular Cell, vol. 21, no. 2, pp. 227-237, 2006.

[107] Y. Yamaguchi, N. Inukai, T. Narita, T. Wada, and H. Handa, "Evidence that negative elongation factor represses transcription elongation through binding to a DRB sensitivityinducing factor/RNA polymerase II complex and RNA," Molecular and Cellular Biology, vol. 22, no. 9, pp. 2918-2927, 2002.

[108] B. M. Peterlin and D. H. Price, "Controlling the elongation phase of transcription with P-TEFb," Molecular Cell, vol. 23, no. 3, pp. 297-305, 2006.

[109] Y. H. Ping, C. Y. Chu, H. Cao, J. M. Jacque, M. Stevenson, and T. M. Rana, "Modulating HIV-1 replication by RNA interference directed against human transcription elongation factor SPT5," Retrovirology, vol. 1, article 46, 2004.

[110] Y. H. Ping and T. M. Rana, "DSIF and NELF interact with RNA polymerase II elongation complex and HIV-1 Tat stimulates P-TEFb-mediated phosphorylation of RNA polymerase II and DSIF during transcription elongation," Journal of Biological Chemistry, vol. 276, no. 16, pp. 12951-12958, 2001.

[111] T. Wada, T. Takagi, Y. Yamaguchi et al., "DSIF, a novel transcription elongation factor that regulates RNA polymerase II processivity, is composed of human Spt4 and Spt5 homologs," Genes and Development, vol. 12, no. 3, pp. 343-356, 1998.

[112] Y. Yamaguchi, T. Takagi, T. Wada et al., "NELF, a multisubunit complex containing RD, cooperates with DSIF to repress RNA polymerase II elongation," Cell, vol. 97, no. 1, pp. 41$51,1999$.
[113] K. Fujinaga, D. Irwin, Y. Huang, R. Taube, T. Kurosu, and B. M. Peterlin, "Dynamics of human immunodeficiency virus transcription: $\mathrm{P}-\mathrm{TEFb}$ phosphorylates $\mathrm{RD}$ and dissociates negative effectors from the transactivation response element," Molecular and Cellular Biology, vol. 24, no. 2, pp. 787-795, 2004.

[114] C. H. Wu, Y. Yamaguchi, L. R. Benjamin et al., "NELF and DSIF cause promoter proximal pausing on the hsp70 promoter in Drosophila," Genes and Development, vol. 17, no. 11, pp. 1402-1414, 2003.

[115] V. Bres, S. M. Yoh, K. A. Jones et al., "The multi-tasking PTEFb complex," Current Opinion in Cell Biology, vol. 20, pp. 334-340, 2008.

[116] N. He and Q. Zhou, "New insights into the control of HIV-1 transcription: When tat meets the 7SK snRNP and super elongation complex (SEC)," Journal of Neuroimmune Pharmacology, vol. 6, no. 2, pp. 260-268, 2011.

[117] Q. Zhou and J. H. N. Yik, "The Yin and Yang of P-TEFb regulation: implications for human immunodeficiency virus gene expression and global control of cell growth and differentiation," Microbiology and Molecular Biology Reviews, vol. 70, no. 3, pp. 646-659, 2006.

[118] D. A. Bisgrove, T. Mahmoudi, P. Henklein, and E. Verdin, "Conserved P-TEFb-interacting domain of BRD4 inhibits HIV transcription," Proceedings of the National Academy of Sciences of the United States of America, vol. 104, no. 34, pp. 13690-13695, 2007.

[119] K. J. Moon, K. Mochizuki, M. Zhou, H. S. Jeong, J. N. Brady, and K. Ozato, "The bromodomain protein Brd4 is a positive regulatory component of $\mathrm{P}-\mathrm{TEFb}$ and stimulates RNA polymerase II-dependent transcription," Molecular Cell, vol. 19, no. 4, pp. 523-534, 2005.

[120] Z. Yang, J. H. N. Yik, R. Chen et al., "Recruitment of P-TEFb for stimulation of transcriptional elongation by the bromodomain protein Brd4," Molecular Cell, vol. 19, no. 4, pp. 535545, 2005.

[121] V. Brès, N. Gomes, L. Pickle, and K. A. Jones, "A human splicing factor, SKIP, associates with P-TEFb and enhances transcription elongation by HIV-1 Tat," Genes and Development, vol. 19, no. 10, pp. 1211-1226, 2005.

[122] V. Brès, T. Yoshida, L. Pickle, and K. A. Jones, "SKIP interacts with c-Myc and Menin to promote HIV-1 Tat transactivation," Molecular Cell, vol. 36, no. 1, pp. 75-87, 2009.

[123] N. He, C. K. Chan, B. Sobhian et al., "Human PolymeraseAssociated Factor complex (PAFc) connects the Super Elongation Complex (SEC) to RNA polymerase II on chromatin," Proceedings of the National Academy of Sciences of the United State, vol. 108, pp. E636-E645, 2011.

[124] B. Sobhian, N. Laguette, A. Yatim et al., "HIV-1 Tat assembles a multifunctional transcription eongation complex and stably associates with the 7SK snRNP," Molecular Cell, vol. 38, no. 3, pp. 439-451, 2010.

[125] T. Ammosova, K. Washington, Z. Debebe, J. Brady, and S. Nekhai, "Dephosphorylation of CDK9 by protein phosphatase $2 \mathrm{~A}$ and protein phosphatase-I in Tat-activated HIV-I transcription," Retrovirology, vol. 2, article 47, 2005.

[126] R. Chen, M. Liu, H. Li et al., "PP2B and PP1 $\alpha$ cooperatively disrupt 7SK snRNP to release P-TEFb for transcription in response to $\mathrm{Ca}^{+}$signaling," Genes and Development, vol. 22, no. 10, pp. 1356-1368, 2008.

[127] N. Epie, T. Ammosova, W. Turner, and S. Nekhai, "Inhibition of PP2A by LIS1 increases HIV-1 gene expression," Retrovirology, vol. 3, article 65, 2006. 
[128] S. Nekhai, M. Jerebtsova, A. Jackson, and W. Southerland, "Regulation of HIV-1 transcription by protein phosphatase 1," Current HIV Research, vol. 5, no. 1, pp. 3-9, 2007.

[129] Y. Wang, E. C. Dow, Y. Y. Liang et al., "Phosphatase PPM1A regulates phosphorylation of Thr-186 in the Cdk9 T-loop," Journal of Biological Chemistry, vol. 283, no. 48, pp. 3357833584, 2008.

[130] T. L. Sung and A. P. Rice, "miR-198 inhibits HIV-1 gene expression and replication in monocytes and its mechanism of action appears to involve repression of cyclin T1," Plos Pathogens, vol. 5, no. 1, Article ID e1000263, 2009.

[131] Z. Zhang, A. Klatt, D. S. Gilmour, and A. J. Henderson, "Negative elongation factor NELF represses human immunodeficiency virus transcription by pausing the RNA polymerase II complex," Journal of Biological Chemistry, vol. 282, no. 23, pp. 16981-16988, 2007.

[132] J. N. Rao, L. Neumann, S. Wenzel, K. Schweimer, P. Rösch, and B. M. Wöhrl, "Structural studies on the RNArecognition motif of NELF E, a cellular negative transcription elongation factor involved in the regulation of HIV transcription," Biochemical Journal, vol. 400, no. 3, pp. 449-456, 2006.

[133] R. A. Marciniak and P. A. Sharp, "HIV-1 Tat protein promotes formation of more-processive elongation complexes," The EMBO Journal, vol. 10, no. 13, pp. 4189-4196, 1991.

[134] Y. Jiang, M. Liu, C. A. Spencer, and D. H. Price, "Involvement of transcription termination factor 2 in mitotic repression of transcription elongation," Molecular Cell, vol. 14, no. 3, pp. 375-385, 2004.

[135] S. Buratowski, "Connections between mRNA 3' end processing and transcription termination," Current Opinion in Cell Biology, vol. 17, no. 3, pp. 257-261, 2005.

[136] E. Rosonina, S. Kaneko, and J. L. Manley, "Terminating the transcript: breaking up is hard to do," Genes and Development, vol. 20, no. 9, pp. 1050-1056, 2006.

[137] S. West and N. J. Proudfoot, "Human Pcf11 enhances degradation of RNA polymerase II-associated nascent RNA and transcriptional termination," Nucleic Acids Research, vol. 36, no. 3, pp. 905-914, 2008.

[138] C. Zhang, K. L. Zobeck, and Z. F. Burton, "Human RNA polymerase II elongation in slow motion: role of the TFIIF RAP74 $\alpha 1$ helix in nucleoside triphosphate-driven translocation," Molecular and Cellular Biology, vol. 25, no. 9, pp. 3583-3595, 2005.

[139] Z. Zhang and D. S. Gilmour, "Pcf11 is a termination factor in Drosophila that dismantles the elongation complex by bridging the CTD of RNA polymerase II to the nascent transcript," Molecular Cell, vol. 21, no. 1, pp. 65-74, 2006.

[140] Z. Zhang, A. Klatt, A. J. Henderson, and D. S. Gilmour, "Transcription termination factor Pcf11 limits the processivity of Pol II on an HIV provirus to repress gene expression," Genes and Development, vol. 21, no. 13, pp. 1609-1614, 2007.

[141] P. Wei, M. E. Garber, S. M. Fang, W. H. Fischer, and K. A. Jones, "A novel CDK9-associated C-type cyclin interacts directly with HIV-1 Tat and mediates its high-affinity, loopspecific binding to TAR RNA," Cell, vol. 92, no. 4, pp. 451462, 1998.

[142] A. Henderson, A. Holloway, R. Reeves, and D. J. Tremethick, "Recruitment of SWI/SNF to the human immunodeficiency virus type 1 promoter," Molecular and Cellular Biology, vol. 24, no. 1, pp. 389-397, 2004.

[143] M. Ott, M. Geyer, and Q. Zhou, "The control of HIV transcription: keeping RNA polymerase II on track," Cell Host \& Microbe, vol. 10, pp. 426-435, 2011.
[144] L. S. Weinberger, J. C. Burnett, J. E. Toettcher, A. P. Arkin, and D. V. Schaffer, "Stochastic gene expression in a lentiviral positive-feedback loop: HIV-1 Tat fluctuations drive phenotypic diversity," Cell, vol. 122, no. 2, pp. 169-182, 2005.

[145] C. Hetzer, W. Dormeyer, M. Schnölzer, and M. Ott, "Decoding Tat: the biology of HIV Tat posttranslational modifications," Microbes and Infection, vol. 7, no. 13, pp. 1364-1369, 2005.

[146] E. Col, C. Caron, D. Seigneurin-Berny, J. Gracia, A. Favier, and S. Khochbin, "The histone acetyltransferase, hGCN5, interacts with and acetylates the HIV transactivator, Tat," Journal of Biological Chemistry, vol. 276, no. 30, pp. 2817928184, 2001.

[147] R. E. Kiernan, C. Vanhulle, L. Schiltz et al., "HIV-1 Tat transcriptional activity is regulated by acetylation," The EMBO Journal, vol. 18, no. 21, pp. 6106-6118, 1999.

[148] M. Ott, M. Schnölzer, J. Garnica et al., "Acetylation of the HIV-1 tat protein by p300 is important for its transcriptional activity," Current Biology, vol. 9, no. 24, pp. 1489-1492, 1999.

[149] S. Pagans, A. Pedal, B. J. North et al., "SIRT1 regulates HIV transcription via Tat deacetylation," Plos Biology, vol. 3, no. 2, article 41, 2005.

[150] N. Sakane, H. S. Kwon, S. Pagans et al., "Activation of HIV transcription by the viral Tat protein requires a demethylation step mediated by lysine-specific demethylase 1 (LSD1/KDM1)," PLoS Pathogens, vol. 7, no. 8, Article ID e1002184, 2011.

[151] K. A. Clouse, D. Powell, I. Washington et al., "Monokine regulation of human immunodeficiency virus-1 expression in a chronically infected human T cell clone," Journal of Immunology, vol. 142, no. 2, pp. 431-438, 1989.

[152] D. G. Brooks, P. A. Arlen, L. Gao, C. M. R. Kitchen, and J. A. Zack, "Identification of $\mathrm{T}$ cell-signaling pathways that stimulate latent HIV in primary cells," Proceedings of the National Academy of Sciences of the United States of America, vol. 100, no. 22, pp. 12955-12960, 2003.

[153] H. C. Yang, S. Xing, L. Shan et al., "Small-molecule screening using a human primary cell model of HIV latency identifies compounds that reverse latency without cellular activation," Journal of Clinical Investigation, vol. 119, no. 11, pp. 34733486, 2009.

[154] V. Planelles, F. Wolschendorf, and O. Kutsch, "Facts and fiction: cellular models for high throughput screening for HIV1 reactivating drugs," Current HIV Research, vol. 9, no. 8, pp. 568-578, 2011.

[155] D. Demonté, V. Quivy, Y. Colette, and C. Van Lint, "Administration of HDAC inhibitors to reactivate HIV-1 expression in latent cellular reservoirs: Implications for the development of therapeutic strategies," Biochemical Pharmacology, vol. 68, no. 6, pp. 1231-1238, 2004.

[156] G. Lehrman, I. B. Hogue, S. Palmer et al., "Depletion of latent HIV-1 infection in vivo: a proof-of-concept study," The Lancet, vol. 366, no. 9485, pp. 549-555, 2005.

[157] J. P. Routy, "Valproic acid: a potential role in treating latent HIV infection," The Lancet, vol. 366, no. 9485, pp. 523-524, 2005.

[158] L. Ylisastigui, N. M. Archin, G. Lehrman, R. J. Bosch, and D. M. Margolis, "Coaxing HIV-1 from resting CD4 T cells: histone deacetylase inhibition allows latent viral expression," AIDS, vol. 18, no. 8, pp. 1101-1108, 2004.

[159] N. M. Archin, M. Cheema, D. Parker et al., "Antiretroviral intensification and valproic acid lack sustained effect on residual HIV-1 viremia or resting $\mathrm{CD}^{+}$cell infection," Plos ONE, vol. 5, no. 2, Article ID e9390, 2010. 
[160] N. M. Archin, J. J. Eron, S. Palmer et al., "Valproic acid without intensified antiviral therapy has limited impact on persistent HIV infection of resting $\mathrm{CD}^{+}{ }^{+} \mathrm{T}$ cells," AIDS, vol. 22, no. 10, pp. 1131-1135, 2008.

[161] N. Sagot-Lerolle, A. Lamine, M. L. Chaix et al., "Prolonged valproic acid treatment does not reduce the size of latent HIV reservoir," AIDS, vol. 22, no. 10, pp. 1125-1129, 2008.

[162] J. D. Siliciano, J. Lai, M. Callender et al., "Stability of the latent reservoir for HIV-1 in patients receiving valproic acid," Journal of Infectious Diseases, vol. 195, no. 6, pp. 833-836, 2007.

[163] A. Steel, S. Clark, I. Teo et al., "No change to HIV-1 latency with valproate therapy," AIDS, vol. 20, no. 12, pp. 1681-1682, 2006.

[164] N. M. Archin, K. S. Keedy, A. Espeseth, H. Dang, D. J. Hazuda, and D. M. Margolis, "Expression of latent human immunodeficiency type 1 is induced by novel and selective histone deacetylase inhibitors," AIDS, vol. 23, no. 14, pp. 1799-1806, 2009.

[165] X. Contreras, M. Schweneker, C. S. Chen et al., "Suberoylanilide hydroxamic acid reactivates HIV from latently infected cells," Journal of Biological Chemistry, vol. 284, no. 11, pp. 6782-6789, 2009.

[166] W. Bernhard, K. Barreto, A. Saunders, M. S. Dahabieh, P. Johnson, and I. Sadowski, "The Suv39H1 methyltransferase inhibitor chaetocin causes induction of integrated HIV-1 without producing a T cell response," FEBS Letters, vol. 585, no. 22, pp. 3549-3554, 2011. 

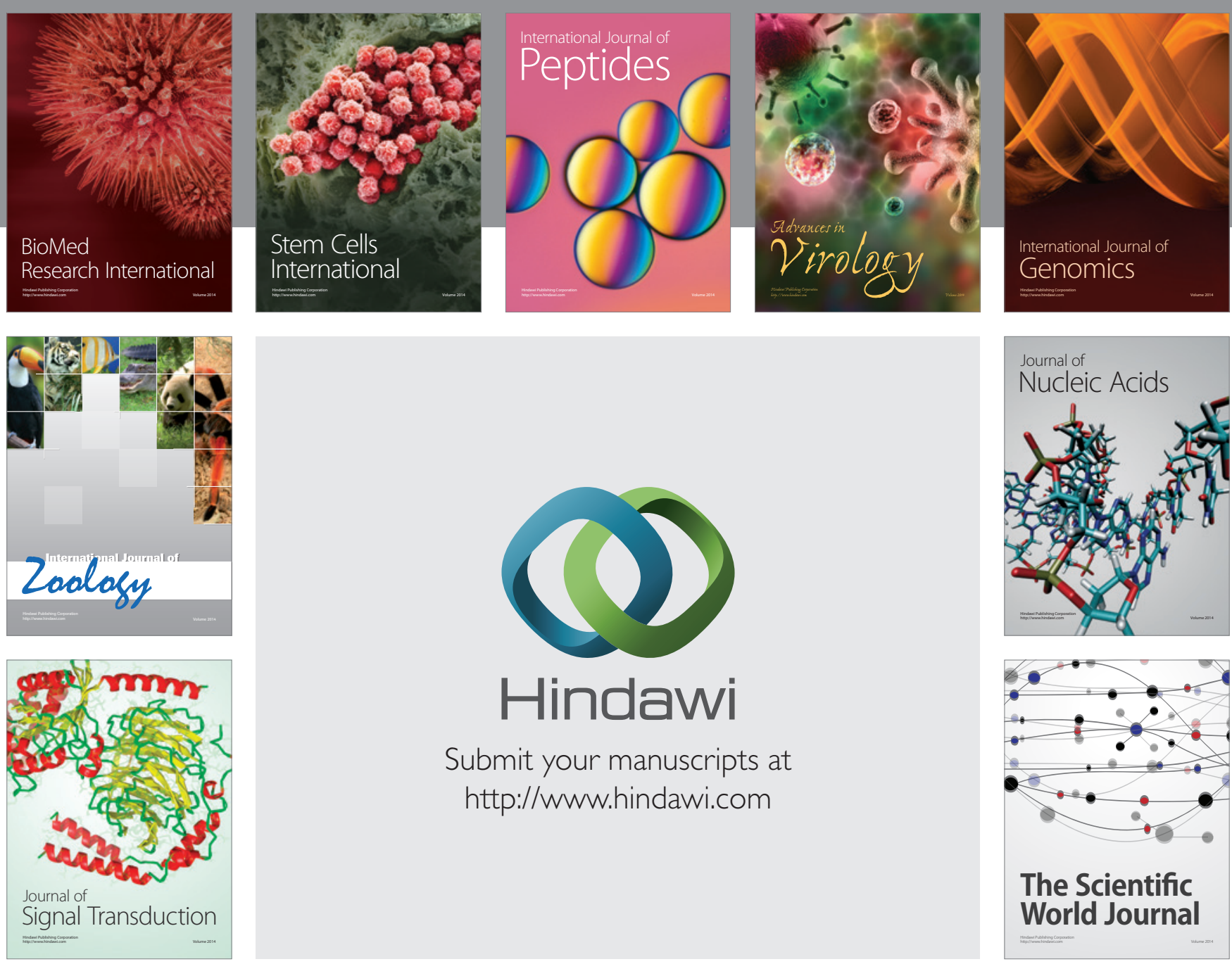

Submit your manuscripts at

http://www.hindawi.com
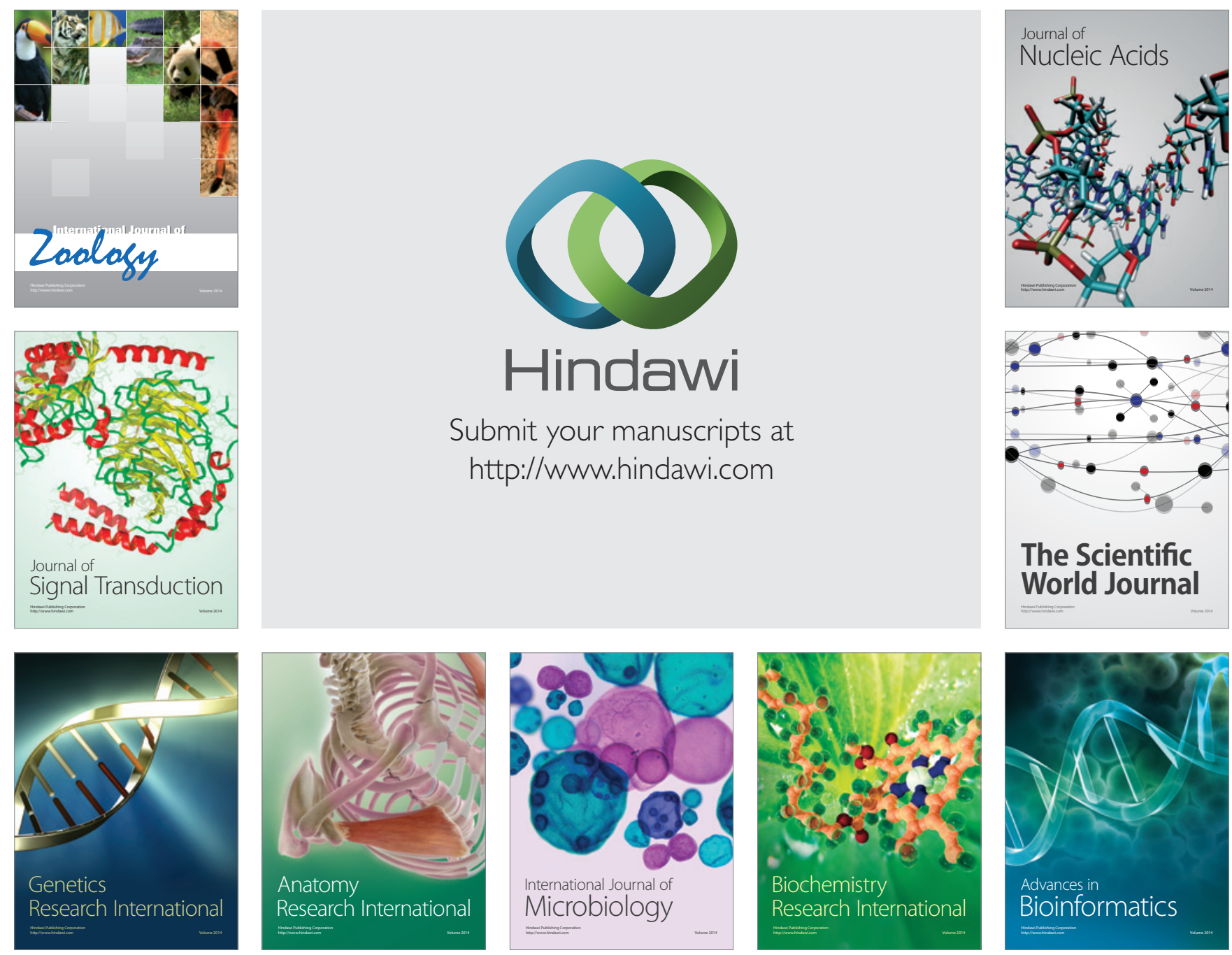

The Scientific World Journal
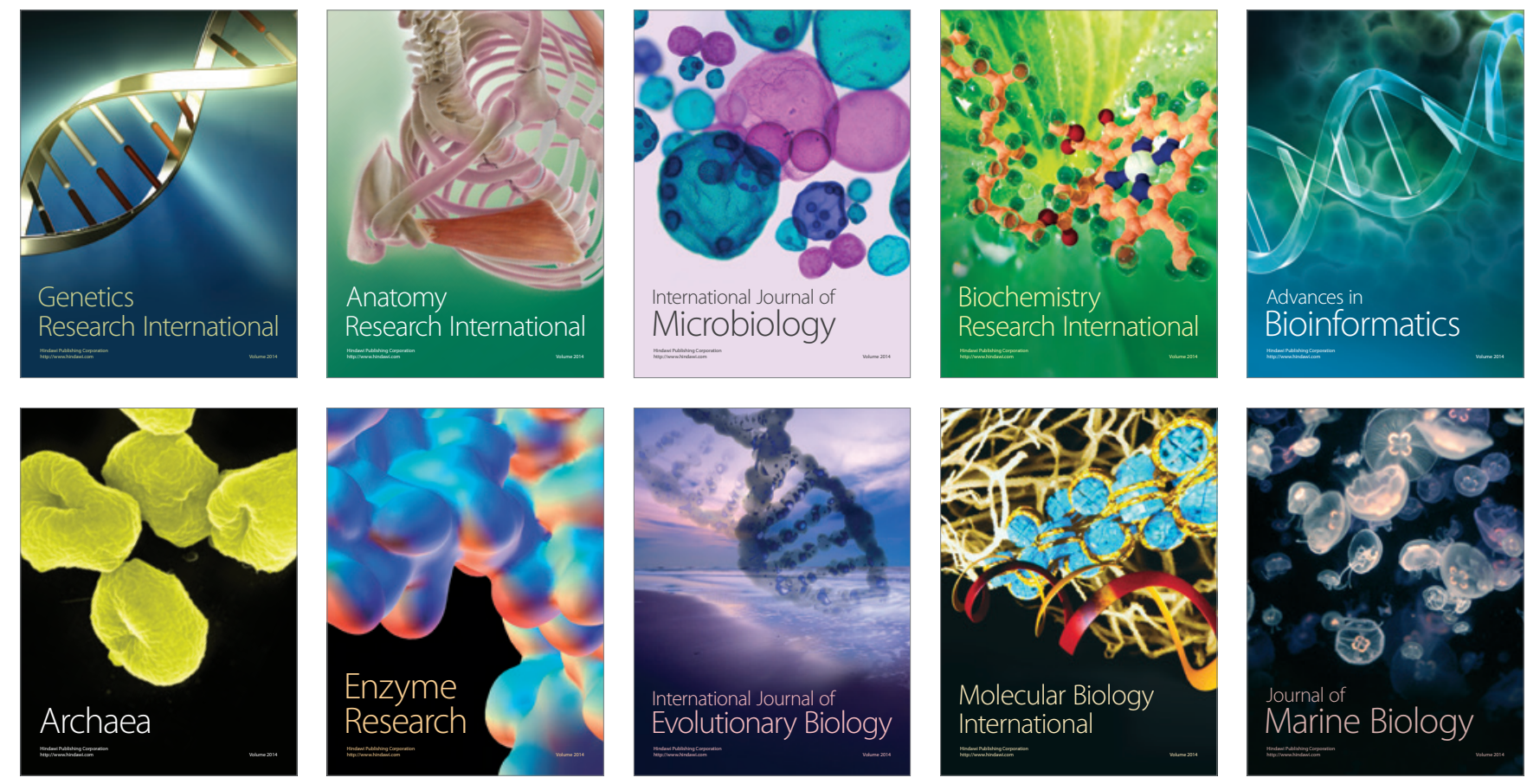